\section{Weapons: the need to replace ageing and deteriorating stock}

SIR - Your Editorial on resistance to non-proliferation of nuclear weapons is, in my view, a good example of selective presentation of data (Nature 461, 11; 2009). As first director of the US Defense Threat Reduction Agency, from 1998 to 2001, I consider a few corrections are in order.

Although the predicted lifetimes of the plutonium pits of US weapons are 40-80 years, the thousands of non-nuclear components in the pit's environment are less stable. Radiation damage, loss of plasticizers and binders, and other changes mean that they could eventually compromise the performance of highly optimized cold-war weapons, designed to minimize weight and use of plutonium and uranium.

Replacing these parts with exact equivalents is often not possible because the materials and production processes no longer exist or because their production is precluded by changes in environmental and safety regulations. Confidence in performance and the willingness of politicians to accept expert judgement about it are likely to suffer.

The proposed Reliable Replacement Warhead (RRW) was designed using nuclear systems that were more robust and had higher margins against failure, thus relaxing the stress on new non-nuclear systems intended for replacement and future production. As a bonus, the safety and surety features of the weapon were improved. It is not a stalking horse for nuclear testing but would increase military and congressional confidence in weapons performance; this assurance is vital as falling numbers render each weapon more important for deterrence.

Unlike the unlamented Robust Nuclear Earth Penetrator, which failed tests of both utility and credibility, the RRW does not represent a lowering of thresholds against nuclear use, nor an opening to worrying policies of pre-emption.

You should not chide the United States for desiring to do what the British, French, Russian and Chinese governments are also doing or planning to do - namely, modernizing their stockpiles with new weapons systems.

Jay Davis Buena Vista Avenue, Livermore, California 94550, USA e-mail: jcd42@sbcglobal.net

\section{Weapons: existing stockpile can be safely maintained}

SIR - You are correct to state that the Reliable Replacement Warhead (RRW) programme would do nothing to improve the reliability of the US nuclear arsenal (Nature 461, 11; 2009). It is possible that the "powerful figures within Obama's own administration" are being advised by people associated with the weapons laboratories who may have an interest in derailing a ratification of the Comprehensive Test Ban Treaty.

Existing nuclear weapons are already very reliable and their safety features are adequate, as a series of reports by R. E. Kidder of Lawrence Livermore National Laboratory affirmed. (For further details, see go.nature.com/yCmG4W.) As US weapons are comfortably tolerant of small variations that may occur in materials or the manufacturing process, they can be remanufactured without explosive proof-testing.

Those in favour of the RRW claim that it would not need nuclear testing. This is because the RRW would be composed of an existing primary stage, which is where many of the uncertainties of nuclear weapons design reside, and probably also an existing secondary stage. However, very few people outside the weapons-design community would trust deployment of a weapon that has not been tested.

As a result, the pressure to test any RRW could well derail the ratification of the test ban treaty. Failing to ratify this treaty (not to mention resuming nuclear testing) would do great harm to US national interests as well as those of the world at large.

Others argue that the RRW programme is needed to maintain expertise in weapons physics. This can be done without the RRW. There is no need for it or any continued nuclear proof-testing.

Gerald E. Marsh East View Park, Chicago, Illinois 60615, USA e-mail:gemarsh@uchicago.edu

Many types of action are required to tackle climate change

SIR — Sanjay Khanna's survey of climate-campaign activities (Nature 461, 1058-1059; 2009) implies that the arts and advertising ought to be helping to bring into being a "worldwide consensus for action". But the point is not to engineer a global consensus for action, as though the 'action' that is being sought is somehow self-evident, unambiguous and uncontested. Palpably, it is not.

Instead, the urgency is to articulate the many types of action - individual or collective, selfish or altruistic, conservative or radical - that can be justified by the prospect of climate change, and to understand why, in a plural and contradictory world, these actions may differ. And then to accommodate them.

To paraphrase one of the six messages that came out of the Copenhagen climate congress in March, it is not inaction that is inexcusable. What is inexcusable is to pretend that there is just one message, one voice, one number to be communicated, that there is just one action agenda that (the science of) climate change demands from us, and that the arts and advertising can deliver it. Mike Hulme School of Environmental Sciences, University of East Anglia, Norwich NR4 7TJ, UK

e-mail:m.hulme@uea.ac.uk

\section{Decarbonization figures for India and China unconvincing}

SIR — In their Opinion articles, Rajendra Pachauri (Nature 461, 1054; 2009) and Jiahua Pan (Nature 461, 1055; 2009) include figures that show business-asusual perspectives on India's and China's emissions growth in coming decades. Both figures indicate that the two countries' economies have already made the transition to high rates of decarbonization. This would put them in a very strong position in international climate negotiations, but I find the figures unconvincing.

India's five business-as-usual projections include different assumptions of annual rates of decarbonization, from $1.0 \%$ up to $3.3 \%$. Four of these greatly exceed the 1987-2006 average of $1.1 \%$. The single businessas-usual projection for China suggests an annual rate of decarbonization of $6.5 \%$ per year to 2030, which is almost three times the 1987-2006 average. China's emissions grew by $12.2 \%$ per year from 2000 to 2007 , and under business-as-usual are now expected to grow by only $2.5 \%$ per year to 2030.

If India and China have indeed already implemented policies that will decarbonize their economies by $3 \%$ per year and more, then it would be very good news indeed, as global rates of about $5 \%$ (or more) per year would be necessary to achieve an $80 \%$ emissions reduction below 1990 levels by 2050, assuming modest economic growth. But if India and China are overoptimistic about future rates of businessas-usual decarbonization, then the challenge of stabilizing concentrations of carbon 


\section{"About $70 \%$ of women holding degrees in science, engineering or technology do not currently work in these fields." Asha Gopinathan, page 165}

dioxide will be much greater.

Either way, projections

of business-as-usual decarbonization from any country that are at rates three times higher than recent historical averages should be greeted with appropriate scepticism.

Roger A. Pielke Jr. Center for Science and Technology Policy Research, UCB 488 University of Colorado, Boulder, Colorado 80309-0488, USA e-mail: pielke@colorado.edu

\section{No special cases in efforts to stop immigration fraud}

SIR - As a scientist working in a foreign laboratory, I can understand Colin Stoneking's frustration at the UK visa system for students (Nature 461, 1053; 2009). However, there is a reason for the unwieldy processes he complains about.

They have been developed to combat the problem of colleges advertising questionable courses to overseas students. In some cases, these are merely fronts to allow economic migrants to circumvent UK border controls, or to defraud overseas students of their tuition fees. A report by the UK Parliament's Home Affairs Committee found that of roughly 4,000 establishments catering to overseas students, 2,200 had not been licensed to sponsor students under the new immigration points system (see go.nature.com/9LXmvd). The implication was that some of them may be, to quote immigration minister Phil Woolas, "dodgy".

The progress of science has always been, and will continue to be, aided by the free exchange of ideas and people between nations. But in the present economic and political climate, we should not expect to be treated as a special case.

lain Scott National Heart, Lung and Blood Institute, 9000 Rockville Pike, Bethesda, Maryland 20892, USA e-mail: scotti@nhlbi.nih.gov

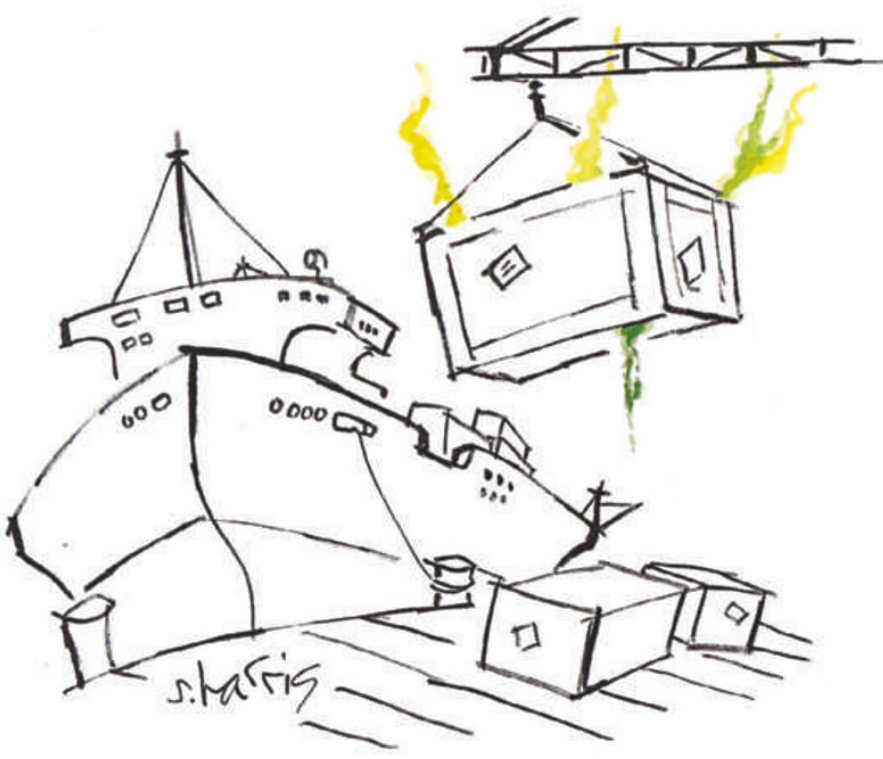

\section{Emissions affected by trade among developing countries}

SIR - As the climate-change conference in Copenhagen approaches, attention is focused on the dialogue between developed and developing countries (see www.nature. com/roadtocopenhagen). But the impact of the growing links between developing countries should not be overlooked.

China is investing heavily in African countries, focusing mainly on improving their infrastructure, as shown by the China Statistical Yearbook 2009 (National Bureau of Statistics of China, 2009). From 1991-2007, imports to China from Africa - chiefly raw materials and emission-intensive products grew by a factor of 45 , compared with just a sixfold increase in imports from the European Union.

Half of China's recent increase in carbon emissions has been driven by its production of goods for export, $60 \%$ of which went to wealthy Organisation for Economic Cooperation and Development (OECD) states (D. Guan et al. Geophys. Res. Lett. 36, L04709; 2009). However China's imports from Africa are responsible for rapidly increasing African carbon emissions from less than 400,000 tonnes to more than 40 million tonnes between 1991 and 2008 (China Statistical Yearbook 2009 and G. P. Peters et al. Environ. Sci. Technol 42, 5; 2008). These already account for $5 \%$ of Africa's total emissions.

Addressing global greenhousegas emissions requires action from developed countries, but also cooperation by developing countries. The more prosperous developing nations have a critical role: by linking resource providers and consumers they can funnel the spillovers of low-carbon technologies to the less developed. Success depends on large-scale financial and technological flow, initiated by OECD countries, with an effective mechanism for sustaining a strong increase in resources and in technology.

Dabo Guan, David M. Reiner Electricity Policy Research Group, Judge Business School, University of Cambridge,

Cambridge CB2 1AG, UK

e-mail:dg346@cam.ac.uk

\section{Phosphorus decline could be good for water supplies}

$\mathrm{SIR}$ - There is an upside to the potential future phosphorus shortage highlighted in your News Feature 'The disappearing nutrient' (Nature 461, 716-718; 2009). Long before a global phosphorus crisis occurs, declining supplies may present a windfall for water quality and sustainable agriculture.

As you point out, declining phosphorus supplies will encourage efficient recycling of phosphorus-rich livestock manure. The full potential of livestock manure fertilizers is not being achieved, owing to unfavourable economics and nutrient ratios that are incongruent with crop needs. The phosphorus-to-nitrogen ratio of livestock manure (roughly 1:3) greatly exceeds the phosphorusto-nitrogen ratio required by common cereal crops such as maize and rice (roughly 1:6). And on multi-operation farms, manure is free.

As a result, manure fertilizer applications often exceed crop phosphorus requirements to meet crop nitrogen demands. The excess phosphorus can be transported to surface waters, fuelling eutrophication of freshwater lakes and low-salinity estuaries such as Lake Victoria and the Stockholm archipelago.

Declining phosphorus supplies coupled with increasing phosphorus demand will encourage sustainable agricultural practices that include more effective manurefertilizer management. For example, livestock manure can be supplemented with synthetic nitrogen fertilizer to narrow the gap between manure and crop nutrient ratios. Better matching of available-nutrient supply with crop-nutrient demand promises to extend global phosphorus supplies and improve water quality throughout the world.

Michael J. Castellano 116 ASI Building, Department of Crop and Soil Science, The Pennsylvania State University, University Park, Pennsylvania 16802, USA e-mail:mjc471@psu.edu

Contributions to this page may be submitted to correspondence@ nature.com. We also welcome comments at Nautilus (http:// blogs.nature.com/nautilus). 